\title{
A FORMAÇÃO DOS EDUCADORES SOCIAIS NO PROGRAMA ESPORTE E LAZER DA CIDADE - PELC - EM PORTO ALEGRE
}

\author{
Recebido em: 15/05/2013 \\ Aceito em: 03/01/2014
}

\author{
Gilmar Tondin ${ }^{1}$ \\ Professor da Prefeitura de Porto Alegre \\ Porto Alegre - RS - Brasil \\ Vicente Molina Neto ${ }^{2}$ \\ Elisandro Schultz Wittizorecki ${ }^{3}$ \\ ESEF/Universidade Federal do Rio Grande do Sul \\ Porto Alegre - RS - Brasil
}

\begin{abstract}
RESUMO: Este artigo procede de uma investigação que teve como foco de estudo a formação de Educadores Sociais do Programa Esporte e Lazer da Cidade, ocorrido em Porto Alegre. O estudo é qualitativo, utilizando-se a entrevista semiestruturada, a análise de documentos e o diário de campo como instrumentos de coleta de informações. O objetivo foi compreender a relação que os Educadores Sociais de Esporte e Lazer estabelecem entre as formações do Programa, e a prática pedagógica realizada junto às comunidades atendidas por estes educadores. As falas e o diálogo com os colaboradores, sustentadas por uma revisão bibliográfica, permitiram compreender a diversidade de atuação e a abrangência social do educador que atua em programas sociais de esporte e lazer.
\end{abstract}

PALAVRAS CHAVE: Políticas Públicas. Esportes. Docentes. Atividades de Lazer.

\section{TRAINING OF TEACHERS OF SOCIAL SPORTS AND LEISURE PROGRAM IN SPORT AND LEISURE CITY - PELC - IN PORTO ALEGRE}

ABSTRACT: This article proposes a research, which aimed to research the formation of Social Educators Sports and Leisure Sports and Leisure Program City, held in Porto Alegre. This is a qualitative study, which used a semistructured interview, the literature review and the field diary as a means of gathering information. Their goal was to understand the relationship of the Social Educators Sporting Goods established between training Program, and pedagogical practice held in the communities served by these educators. The speeches and dialogue with employees, supported by a literature review

\footnotetext{
${ }^{1}$ Mestre em Ciências do Movimento Humano pela Universidade Federal do Rio Grande do Sul.

${ }^{2}$ Doutor em Filosofia e Ciências da Educação pela Universidad de Barcelona.

${ }^{3}$ Doutor em Ciências do Movimento Humano pela Universidade Federal do Rio Grande do Sul.
} 
allowed us to understand the diversity of expertise and scope of the social educator who works in social programs of sport and leisure.

KEYWORDS: Public Policies. Sports. Faculty. Leisure Activities.

\section{INTRODUÇÃO}

Neste artigo apresentamos uma investigação realizada no âmbito da formação de Educadores Sociais de Esporte e Lazer, realizada no Programa Esporte e Lazer da Cidade (PELC), em Porto Alegre, no período de junho de 2008 a junho de 2009.

O programa do Ministério do Esporte (ME) - PELC - surgiu em 2003 (CASTELLANI FILHO, 2007), com o objetivo de suprir a carência de políticas públicas e sociais para atender demandas da população por esporte recreativo e lazer (BRASIL, 2008). Nesse texto, partimos do entendimento de política pública como as escolhas de um governo, as relações que este governo estabelece com as questões públicas, e as ações do governo que incidem diretamente na população, (SOUZA, 2006).

Do ponto de vista democrático, Souza (2006, p. 04) salienta que a "formulação de políticas públicas constitui-se no estágio em que os governos democráticos traduzem seus propósitos e plataformas eleitorais em programas e ações que produzirão resultados ou mudanças no mundo real”. Assim, essa conceituação traduz a compreensão de que a Política Pública é toda a ação pública, em qualquer nível, formada por um conjunto de medidas concretas e que apresentam visibilidade, que pode ser constituída de recursos financeiros, intelectuais, reguladores e materiais (MULLER e SUREL, 2002).

Sob a ótica de Pereira-Pereira (2009), existem duas interpretações, as mais difundidas, sobre Política Pública: uma destaca a ação do Estado como elaborador único dessas políticas. Nesse caso, o público é confundido com o estatal. E a outra estabelece 
a relação dialeticamente contraditória entre o Estado e a sociedade. Dessa forma, estabelecendo-se que Política Pública não é exclusividade do Estado, mas a construção entre o Estado e a sociedade, o vocábulo público é muito mais democrático e abrangente do que o termo estatal.

A Política Pública, da qual se compartilha de seus pressupostos, é aquela em que o termo público se refere a todos, não apenas ao Estado, ou a grupos específicos e até mesmo a interesses individuais. O caráter público deve ser dado a partir de algumas características: (1) ter uma linha de orientação sob a responsabilidade pública e o controle da sociedade; (2) concretização de direitos sociais conquistados pela sociedade, materializados em programas, projetos e serviços; (3) guiar-se pelo interesse público e não pelo particular; e, (4) visar à satisfação das respostas sociais em detrimento do econômico.

Nesse sentido, o PELC se constitui como uma ação derivada da política pública de esporte e lazer deste momento histórico, sustentada por uma concepção de papel do Estado e seus compromissos sociais. O programa prevê uma formação pedagógica, modular, com o objetivo de preparar os Educadores Sociais de Esporte e Lazer para atuarem junto às comunidades, em especial as da periferia da cidade. Neste artigo procuramos analisar a seguinte questão: de que modo os Educadores Sociais de Esporte e Lazer relacionam a formação do PELC e a prática pedagógica que realizam nas comunidades?

Constituíram fontes de pesquisa a entrevista semiestruturada, documentos orientadores do PELC e o diário de campo.

Assim, o artigo está estruturado da seguinte forma: em primeiro momento apresentamos brevemente a estruturação e fundamentação do PELC; na sequência, 
discutimos os referenciais que nos apoiaram na compreensão do processo de formação dos Educadores Sociais de Esporte Lazer e suas possibilidades no campo do lazer. Em seguida, descrevemos as decisões metodológicas que sustentaram o trabalho de campo. Logo após, apresentamos a análise e discussão dos achados empíricos em duas seções: a formação dos Educadores Sociais de Esporte e Lazer e sua prática pedagógica. Por fim, concluímos com nossas considerações transitórias e as referências.

\section{ESTRUTURAÇÃO E FUNDAMENTAÇÃO DO PROGRAMA ESPORTE E LAZER DA CIDADE}

O PELC é um programa da Secretaria Nacional do Esporte, Educação, Lazer e Inclusão Social (SNELIS) ${ }^{4}$ do ME e, para melhor compreender a realização deste Programa, é importante identificar as bases teóricas que sustentam sua estruturação e funcionamento, iniciando-se pelas concepções de lazer e esporte que pautam as ações desse Programa.

O Lazer é um fenômeno da sociedade moderna, desenvolvido pelas relações e tensões entre capital e trabalho (MASCARENHAS, 2005a). Ele tem sido objeto de estudos acadêmicos (ISAYAMA e SILVA, 2011; MARCELLINO, 2009; PINTO, 2006; MASCARENHAS, 2005b; GOMES e MELO, 2003; STIGGER, 2002) pela sua diversidade de conteúdos e de possibilidades de atuações profissionais. Conforme Padilha (2006), o lazer comporta uma polissemia, agrega vários conceitos e sua compreensão pode ocorrer a partir do entendimento de mundo em que os sujeitos vivem e sobrevivem. Para o ME o lazer é assim conceituado:

\footnotetext{
4 Até julho de 2011 esta Secretaria era denominada de Secretaria Nacional de Desenvolvimento do Esporte e do Lazer (SNDEL).
} 
A cultura vivida com alegria e liberdade no tempo disponível e fora das obrigações sociais. Tempo, espaço e oportunidade privilegiados para vivências lúdicas, para divertir-se de diferentes modos, participar de diferentes formas (assistindo, praticando e conhecendo) em diferentes espaços. Como fator de qualidade de vida, o lazer é compreendido como meio e fim educativos para a formação de valores e pode contribuir para o desenvolvimento social, cultural e humano (BRASIL, 2010b, p.17).

É com base nesse conceito de lazer que o PELC se pauta: lazer como processo de desenvolvimento humano, em uma perspectiva crítica, buscando a realização pessoal e social dos indivíduos. Também é possível pensar o lazer como utopia (MASCARENHAS, 2005b), com a possibilidade de sonhar com a construção cidadã, na qual, além de outras reivindicações, possa aparecer o direito ao lazer; e esse estar a serviço do bem comum, da promoção pessoal e da autoestima, um espaço de construção coletiva e individual, crítica e criativa para todos.

O entendimento de esporte em sua dimensão de lazer - apontado nos documentos orientadores do Programa - o coloca com a finalidade de atender os interesses e necessidades sociais dos cidadãos a partir da prática das suas manifestações lúdicoesportivas, de fruição do espetáculo esportivo e do conhecimento dela imanado (BRASIL, 2005), pois, "o esporte, construção humana historicamente criada e socialmente desenvolvida, é abordado como integrante do acervo da cultura da humanidade [...]" (BRASIL, 2005, p. 22). Nesse sentido, o esporte de lazer ou, dito de outra forma, esporte recreativo é definido como a dimensão do esporte a ser praticada no PELC com o seguinte conceito:

\footnotetext{
Dimensão social do esporte, na qual a prática se dá de maneira redimensionada, recriada e reinventada, não restrita às delimitações das regras oficiais, o que permite aos participantes usufruírem atividades lúdicas, prazerosas, solidárias e de enriquecimento cultural, favorecendo $\mathrm{o}$ desenvolvimento de senso crítico, autonomia e sensibilidade frente às questões sociais. Não tem caráter competitivo nem seletivo (BRASIL, 2010a, p.17).
}

Tal concepção se aproxima da perspectiva de Bracht (1989) quando argumenta que é no esporte de lazer que existe possibilidade de o sujeito construir a sua autonomia 
cultural, através da autogestão, no sentido da criação ou recriação para desenvolver o seu esporte e, quem sabe, exercitar a contra-hegemonia cultural.

O Ministério do Esporte organizou ações estruturantes para qualificar a execução desse Programa: o financiamento para aquisição de material esportivo e de lazer; a contratação de educadores sociais para atuarem nas comunidades; e a qualificação desses educadores através de formações continuadas, ministradas pelos Formadores do PELC. A formação dos Educadores Sociais de Esporte e Lazer ocupa, segundo o ME, lugar estratégico e fundamental para viabilizar essa política social.

Na revisão bibliográfica nota-se que não há uma unidade de opiniões sobre o perfil desse sujeito, sobre a estrutura de formação e sobre a denominação desse educador, destacando-se: as noções de animador (CAMARGO, 2011), animador cultural (MELO, 2006), animador sociocultural (MARCELLINO, 2003a), agente social de esporte e lazer (BRASIL, 2008) e trabalhadores do lazer (SUASSUNA, 2009).

Aqui, quando se faz referência aos sujeitos que trabalham no PELC, em particular aos professores de educação física que atuam nas comunidades e com atribuições pedagógicas, serão denominados de Educadores Sociais de Esporte e Lazer. Diferenciam-se do educador que atua em ambientes escolares pela característica do espaço físico de sua atuação, definido, aqui, como ambiente não escolar (MOURA e ZUCHETTI, 2006). Esse entendimento aproxima-se do estudo realizado por Schaff (2010) ao analisar a formação permanente de professores de educação física que atuam em ambientes não escolares e suas relações com a prática pedagógica, o autor sugere que a diferença na sua atuação pedagógica e na relação educador/aluno é o ambiente físico. 
Para viabilizar a formação do PELC, o ME organizou um conjunto de medidas com o propósito de materializar essa intenção, criando o Sistema de Formação. Conforme os documentos que orientam o Programa, esse sistema de formação tem o objetivo de aproximar a ação que o educador social de esporte e lazer desenvolve nas comunidades com os princípios e diretrizes do PELC. Elas ocorrem em três módulos: introdutório; de aprofundamento/formação em serviço; e módulo de avaliação. Para desenvolver as formações (módulo introdutório e de avaliação) há um grupo de formadores credenciados pelo ME, e somente eles poderão trabalhar nessas formações.

Os formadores do PELC são os responsáveis pelas formações dos módulos introdutórios e de avaliação. As formações em serviço são de responsabilidade do gestor local.

\section{FORMAÇÃO DOS EDUCADORES SOCIAIS DE ESPORTE E LAZER}

Ainda que este trabalho trate da formação dos educadores sociais de esporte e lazer no âmbito de sua realização no PELC na cidade de Porto Alegre/RS, nos dedicamos nesta seção a examiná-la, considerando que esse processo não se inicia e nem se conclui em tal Programa. Essa formação se produz, também, de modo articulado ao percurso e a tradição da própria área da Educação Física e, mais recentemente, mobilizada por políticas públicas de esporte e lazer no país.

Para compreender a formação do educador, busca-se entender a formação do professor de educação física. Molina Neto et al. (2006), analisaram a constituição da educação física e do seu currículo nas universidades, desde a origem e sua relação com o meio militar, até a atual dicotomia que se expressa em uma mesma instituição, formar licenciados e bacharéis. Apontam esses elementos como "ingredientes mais do que 
suficientes para caracterizar uma crise na formação inicial em educação física" (p. 50), e que a busca do professorado, pela formação permanente é uma possibilidade de suprir a formação inicial insuficiente.

Para Hernández (2004, p. 55) “os docentes, quando aprendem, não tendem a fazêlo em termos de teoria, mas de prática", pois, a visão que valoriza o fazer é considerada essencial na tarefa dos professores. Os docentes têm uma visão prática de sua atuação, a qual está impregnada de experiências vividas e experimentadas em seu dia-a-dia. Salienta, ainda, que não há evidências da relação entre o que é desenvolvido nas formações e a efetiva aprendizagem dos professores.

Sobre a formação de educadores para atuarem na área específica de lazer e esporte, Marcellino (2009) aponta para uma nova pedagogia [grifo do autor], denominada "Pedagogia da Animação", na qual procura estabelecer uma relação entre os conteúdos do lazer e os demais conteúdos escolares, considerando o lazer um "canal viável de atuação no plano cultural, de modo integrado com a escola. Dessa forma, continua o autor, "o lazer poderia contribuir para a elevação do senso comum, numa perspectiva de transformação da realidade social" (p. 18). O próprio autor considera utópica essa possibilidade, mas acredita nela, como o processo de uma caminhada histórica que pode ser materializada se houver sujeitos - educadores - para realizarem o projeto.

Isayama (2003) destaca a importância de se repensar o processo de atuação do educador social que atua no lazer, processo, muitas vezes, considerado "fácil" e "gostoso" de ser realizado, e a grande maioria desses educadores ignora a necessidade de fundamentos técnicos, pedagógicos, políticos e sociais em sua atuação. 
No entender de Marcellino (2007, p.16), "existe um discurso de que o bom humor é mais fundamental que competência para atuar com o lazer", como se a característica pessoal fosse mais importante do que conhecimentos e aprendizagens. Para trabalhar com lazer bastaria saber distrair bem o público e o educador já seria considerado um bom profissional, assumiria o papel de quase um "bobo-da-corte", desprovido de qualquer intencionalidade pedagógica consciente de atuação política.

Com base nessas considerações se reforça a ideia da formação específica para educadores que trabalham com o lazer e o esporte. Um dos pilares de uma política pública de lazer, diz Marcellino (2008b), “é uma política de formação de quadros" (p.34). E quando o autor se refere ao profissional de lazer é contundente na afirmação desse sujeito como educador, no sentido mais amplo da palavra, como o sujeito que tem a possibilidade de protagonizar momentos de mudanças em uma nova relação social entre os sujeitos. Ao se referir e valorizar a formação de educadores de esporte e lazer, o autor lhes atribui, além da seriedade e da competência, o compromisso político, sem confundi-lo com o político-partidário, mas o de não aceitar a condição de tarefeiro. Ao contrário, deve encarar sua atuação como um ato pedagógico consciente e crítico.

Sobre a formação desses educadores, Melo e Alves Junior (2003), Isayama (2003) e Marcellino (2008a) enfatizam a necessidade de uma formação específica, contrária a uma compreensão distorcida em que atuar nessa área é uma tarefa fácil e simples. No entanto, para se construir e desenvolver um "outro lazer" (MASCARENHAS, 2005b) é necessário visualizar o lazer como integrante do campo das políticas sociais e fator de promoção das relações humanas. Compreender o lazer como produto de consumo é o mesmo que afastá-lo de valores como participação, liberdade e transformação, e 
vinculá-lo à condição de classe social de indivíduos ou grupos, como fator excludente e segregador (PELLEGRIN, 2006).

Nesse processo de gestação de novas possibilidades de mudanças, o educador social de esporte e lazer tem papel fundamental: mediante questionamentos, reflexões, indicando limites e buscando superá-los, mas, sobretudo, articulando e revelando as relações entre a sociedade e os indivíduos. A sua forma de interagir no mundo contribui para que, politicamente, sejam possíveis novos graus de maturidade e novas formas de manejo da educação, do trabalho e do lazer.

\section{DECISÕES METODOLÓGICAS}

Partindo-se do exame das premissas de esporte e lazer que orientam a realização do PELC e do entendimento da complexidade de formar educadores que deem conta de tal Programa, buscamos compreender de que modo os Educadores Sociais de Esporte e Lazer relacionam a formação realizada pelo PELC com sua prática pedagógica realizada nas comunidades.

Para atingir tal objetivo investimos em um estudo descritivo-explicativo de caráter qualitativo, pautado na compreensão de que a investigação qualitativa é “descritiva” (BOGDAN; BIKLEN, 1994, p. 48) porque as informações coletadas para a análise estão "na forma de palavras ou imagens e não de números", e podem ser descritas através das entrevistas, notas de campo, fotografias, vídeos e documentos pessoais e oficiais, cuja articulação entre si permitirá ler e interpretar a realidade sensível.

Para obter as informações foram utilizados os seguintes instrumentos: a análise de documentos, a entrevista semiestruturada e as anotações registradas no diário de 
campo. Os documentos analisados foram: Programa de Formação dos Agentes Sociais de Esporte e Lazer do Programa Esporte e Lazer da Cidade (BRASIL, 2008), Orientações para implantação do PELC (BRASIL, 2010a) e Política Intersetorial: PELC e PRONASCI (BRASIL, 2010b).

Essas informações, mais o referencial teórico acerca do tema investigado constituíram-se os elementos que sustentaram as análises dos achados deste estudo.

A eleição dos colaboradores foi feita a partir de sua representatividade tipológica (MOLINA NETO, 2004), identificando-se os diferentes sujeitos, nos diferentes segmentos da pesquisa e que tivessem participado das formações ministradas pelos formadores do ME. Essa representatividade considerou os seguintes critérios para a escolha dos colaboradores, apresentados no (QUADRO 1):

a) Professores (as) de educação física.

b) Professores (as) com tempos de experiência diferentes; com até quatro anos de experiência, e com mais de dez anos de experiência de profissão.

c) Professores (as) nas diferentes funções no PELC:

Quadro 1: Caracterização dos colaboradores e cronograma de entrevistas

\begin{tabular}{lcccc}
\hline Nome Fantasia $^{\mathbf{5}}$ & Função no PELC & Idade & Tempo de experiência \\
\hline LAURO & Coord. Nacional PELC & 48 anos & 23 anos \\
CLAUDIA & Coord. Geral PELC Porto & Não informado & 20 anos \\
& Alegre & 51 anos & 20 anos \\
LIVIA & Formadora PELC & 55 anos & 31 anos \\
NEIVA & Formadora PELC & 31 anos & 2 anos \\
ARTUR & Coord. Núcleo & 29 anos & 1 ano \\
ANGELA & Coord. Núcleo & 24 anos & 2 anos \\
ROMEU & Professor & 30 anos & 3 anos \\
LUCIO & Professor & 50 anos & 27 anos \\
CARLA & Professora & 43 anos & 11 anos \\
SARA & Professora & &
\end{tabular}

\footnotetext{
${ }^{5}$ Os nomes dos colaboradores foram modificados para preservar a sua identidade.
} 
A análise das informações foi realizada com a construção de categorias de análise, "resultantes de processo analítico das informações coletadas em diálogo com as contribuições do aporte teórico" (WITTIZORECKI, 2009, p. 62). Para a análise das informações foi necessário organizar e definir dois grupos:

Grupo dos Gestores e Formadores: constituído pelos dois coordenadores, nacional e local, do PELC e pelos formadores (que não atuavam diretamente com a comunidade).

Grupo de Educadores do PELC: composto pelos coordenadores de núcleos e os professores. A atuação dos integrantes deste grupo ocorreu diretamente com as comunidades.

Com a preocupação de construir um caminho de coerência às reflexões do estudo, utilizamos a validez interpretativa para conferir fidelidade e credibilidade aos achados do campo (MOLINA NETO, 2004). Dessa forma, submetemos o conteúdo das entrevistas aos respectivos colaboradores para que pudessem ler, revisar, retirar e acrescentar relatos que julgassem pertinentes; procedemos a triangulação de dados, com o "objetivo de abranger a máxima amplitude na descrição, explicação e compreensão" (TRIVIÑOS, 2009, p. 138) das informações obtidas a partir das entrevistas, dos registros no diário de campo, das contribuições dos referenciais teóricos consultados e dos documentos que fundamentam pedagógica e administrativamente o PELC; submetemos a redação parcial e final da investigação à análise de dois educadores sociais, professores de educação física (um com conhecimento e aproximação com o tema e o outro com experiência de 25 anos de trabalho em ensino de Educação Física). 
Considerando-se o problema de pesquisa, em que se busca compreender quais relações os Educadores Sociais de Esporte e Lazer estabelecem entre a formação do PELC e a práticas pedagógicas que realizam nas comunidades, construímos as seguintes categorias de análise: a) A Formação no PELC; b) O lazer e o esporte no PELC; c) Prática pedagógica; d) A Comunidade; e, e) A Gestão local do programa.

Por razões de espaço e profundidade nas reflexões, neste artigo são discutidas as categorias Formação no PELC e a Prática Pedagógica dos Educadores Sociais que atuam nesse Programa.

\section{FORMAÇÃo PEDAGÓgICA NO PROGRAMA ESPORTE E LAZER DA CIDADE - relações e significados}

Com base na análise dos documentos orientadores do Programa, no referencial teórico e nas manifestações dos colaboradores, nessa categoria apresentamos algumas relações que os Educadores Sociais de Esporte e Lazer estabelecem entre as formações do PELC e a sua prática pedagógica, visibilizando os significados que eles atribuem a essas formações.

Para melhor exposição e compreensão das informações obtidas no trabalho de campo, apresentamos as considerações dos colaboradores sobre o processo de formação dos Educadores Sociais de Esporte e Lazer e as interpretações em dois grupos: de um lado, gestores e formadores; de outro, os Educadores Sociais de Esporte e Lazer. Tal distinção permite ressaltar o olhar de cada grupo, estando em lugares diferentes, sobre um mesmo objeto.

É possível pensar que o educador busca, durante o processo permanente de sua formação, a autonomia docente, a segurança de estar frente a frente com seus alunos e 
dominar aquele conhecimento que, necessariamente, passa pelo controle da ação prática. Esse domínio lhe conferirá segurança para assumir com autonomia o controle de um grupo de alunos e decidir com os participantes que conhecimentos serão trabalhados e quais estratégias didático-pedagógicas serão desenvolvidas Essa é a demanda premente do educador frente a uma situação inédita ou permeada de outras características que sugerem conflitos ou desafios.

Por outro lado, a intencionalidade do sujeito que organiza a aprendizagem na formação é a de buscar a reflexão sobre a prática do sujeito que a recebe, porque estão em papéis distintos, em momentos distintos de um mesmo processo. Hargreaves (1996, p.19) considera que o elemento tempo é muito importante no trabalho dos professores, por estruturar a ação docente. Paradoxalmente, é comum que o gestor se mostre pouco sensível ante a perspectiva temporal subjetiva do educador e às condições de trabalho que, provavelmente, podem gerar grande consequência na gestão e no processo educativo.

\section{Gestores e Formadores}

No sistema de formação do PELC, o formador ocupa o lugar do elemento de ligação, do ponto de vista político-pedagógico, entre o ME e os Educadores Sociais de Esporte e Lazer. Portanto, ele também é sujeito do processo de formação.

No entendimento do colaborador Lauro (2011), as formações têm cumprido importante papel para esclarecer e informar sobre novos conceitos. Muitos educadores chegam às formações, por exemplo, com uma concepção de esporte mais voltado para o rendimento. Com isso, além dos conceitos novos, era necessário desconstruir alguns antigos, mas, ao mesmo tempo, colocava-se em dúvida o êxito desse propósito dado o 
curto espaço de tempo das formações ${ }^{6}$. O colaborador Lauro (2011) considera que a abrangência e a diversidade de conteúdos tratados e o pouco tempo para discussão não favoreceram a compreensão necessária para o desenvolvimento do programa, como se pode notar em sua manifestação:

[...] elas não esperavam que a formação fosse aquilo, elas tinham uma visão diferenciada sobre o esporte. Não que mude totalmente, algumas acabam a formação insistindo que vão fazer uma escolinha, e querem que os alunos, são "alunos", um dia sejam um atleta profissional.[...] A gente tem a expectativa de querer construir muitos conceitos novos num período que não tem condição, porque a pessoa tá ali e nunca tinha ouvido falar daquilo (LAURO, entrevista janeiro/2011).

Transformar, da mesma forma que ensinar, diz Freire (2007), exige paciência, e possivelmente isso faça a diferença entre a mudança e a manutenção do status quo não apressar um processo que necessita de tempo para assimilação e muita reflexão para permitir a possibilidade de mudança de consciência. É o que diz o colaborador Lauro:

\begin{abstract}
A formação acho que marca a diferença. Porque a decisão de que a execução do programa depende do processo de formação dos educadores, prá que eles tenham conhecimento da estrutura, prá que eles escutem os conceitos que são estruturantes do programa é importante (entrevista janeiro/2011).
\end{abstract}

As formações, por serem espaços de construção de sujeitos, a partir da reflexão sobre teorias e ações, de trocas de saberes, se constituem momentos de um processo de desenvolvimento político-pedagógico que se reflete em todos os momentos da sua vida profissional e pessoal. As manifestações que aparecem nas falas dos colaboradores reforçam essa compreensão. Quando o colaborador fala sobre autocrescimento, colocase na posição de sujeito do processo, com a consciência de que o ato de ensinar também é um ato de aprender (FREIRE, 2007). A manifestação de Neiva caminha por essa perspectiva:

\footnotetext{
${ }^{6}$ Formação do Módulo Introdutória: 32 horas. Neste módulo são apresentados a concepção pedagógica e os conceitos do programa.
} 
Porque cada um com sua experiência profissional, com suas experiências de vida, com as suas leituras, com a sua formação, soma com a formação do outro. É uma experiência rica, no sentido também da gente trocar experiências, porque quando se vai fazer as formações, a gente ensina, mas se aprende o tempo todo. (entrevista janeiro/2011).

O desenvolvimento profissional e pessoal dos integrantes desse grupo, a partir da experiência vivenciada no PELC, é unânime em sua perspectiva; unânimes também são as manifestações de envolvimento afetivo com o programa, mesmo daqueles que, no momento da pesquisa, não estavam mais vinculados ao sistema de formação.

\section{Educadores Sociais de Esporte e Lazer}

As falas dos colaboradores sobre a formação do módulo introdutório mostram o significado do primeiro contato com o PELC. Para o colaborador Artur (2010), as informações iniciais trabalhadas ao longo da formação foram importantes para o entendimento dos objetivos do programa, sua origem, qual a função dos educadores e das coordenações de núcleos. Ao mesmo tempo, considera que a formação poderia ter avançado nas questões das relações do grupo, com o objetivo de integrar os colegas, pois esse é o seu primeiro contato com o programa e entre os Educadores Sociais de Esporte e Lazer.

Mesmo considerando importante a definição de conceitos e os conteúdos teóricos para o trabalho na comunidade, o que interessava, majoritariamente, para os Educadores Sociais de Esporte e Lazer eram as atividades práticas e especialmente as trocas, as experiências vividas e as possibilidades de soluções para os problemas do cotidiano. Tal interesse derivava de uma preocupação do educador em estabelecer um clima cordial no trabalho, formar uma equipe com uma boa relação de amizade, trocar experiências e aprender novas brincadeiras e atividades. Ilustra o colaborador Artur: 


\begin{abstract}
A formação foi mais no sentido de transmitir algum conhecimento teórico, vamos dizer assim, [...] mas bom seria ensinar brincadeiras ou coisas que podem ser feitas..., E aí aconteceram algumas coisas legais, que eu achei importante, dos próprios educadores do PELC contarem a sua experiência, o que aconteceu no dia a dia, qual a metodologia que ele usava. Como ele fez para superar determinado problema. Isso eu achei mUito legal [...] (entrevista março/2011).
\end{abstract}

No entanto, para o colaborador Romeu (2011), as formações foram pouco atrativas porque houve poucas atividades práticas. A relação e o significado de uma boa formação passavam pelo desenvolvimento de conteúdos de dimensão prática.

O trabalho de campo permitiu apreender que os educadores sociais parecem não considerar o seu conhecimento singular, a sua experiência, como elementos legítimos do seu desenvolvimento profissional. O seu saber, em seu imaginário, é menor; o saber do outro, neste caso, o acadêmico, parece ter maior significado. O critério de validade do conhecimento é atribuído ao outro (formador) e pouco a si próprio.

Esse descompasso entre o ideal e o real, entre teoria e prática, identificado com muita frequência na área de esporte e lazer (EWERTON, 2010), surge nas manifestações da maioria dos colaboradores desse grupo, os quais esperam encontrar, nas formações, algumas prescrições para colocarem em prática em suas aulas. Não se percebem manifestações sobre questionamentos teóricos ou reflexões a partir das ações; a análise crítica a partir ação-reflexão-ação não é identificada, ao contrário, surgem manifestações como a de Romeu:

Eu acho mais importante do que tu pegar um livro, ou do que tu ver um professor falando, ou formador falando..., é trocar experiência. Eu acho que a experiência vai fazer tu crescer profissionalmente. Daí a teoria se busca depois, né. E aí no livro tu vai ver direitinho quais são os caminhos, (entrevista abril/2011).

O que parece ter mais significado para os colaboradores do estudo são as vivências nas formações, as atividades práticas que respondem a duas demandas dos Educadores Sociais de Esporte e Lazer: novas ideias e sugestões de atuação com os alunos, e, através delas, maior integração entre os colegas. 
Os Educadores Sociais de Esporte e Lazer não parecem estar dispostos a discutir e a tratar de assuntos que não estejam diretamente ligados à sua prática pedagógica no cotidiano com as comunidades. As metodologias de ensino vivenciadas ao longo das formações parecem ter sido mais significativas que os conteúdos. Em outras palavras, para os Educadores Sociais de Esporte e Lazer, as metodologias de ensino tiveram mais importância para sua ação na relação com a comunidade. As reuniões pedagógicas sistemáticas que ocorriam semanal ou quinzenalmente, de acordo com o critério de cada núcleo, eram concebidas, na perspectiva do gestor, como momento de formação. No entanto, não eram compreendidas pelos Educadores Sociais de Esporte e Lazer como tais.

\section{PRÁTICA PEDAGÓGICA}

Nessa seção o objetivo é compreender de que modos os conceitos, as discussões, as reflexões e as práticas desenvolvidas nas formações interferem no modo de pensar e agir do Educador Social de Esporte e Lazer em sua prática pedagógica.

A prática pedagógica tem uma série de condicionantes anteriores e que são determinantes para a realização do trabalho docente. São as condições sociopolíticas que incidem e influenciam a concepção de homem e sociedade, os pressupostos sobre educação e aprendizagem, as relações professor-aluno, conteúdos, técnicas pedagógicas, entre outros (LIBÂNEO, 1995). Quando o educador se prepara para a prática pedagógica, consciente ou inconsciente, ela estará revestida com todos esses condicionantes. Concordamos com Libâneo (1995), no entendimento de prática pedagógica, quando o autor diz que

[...] não se trata, apenas, da transmissão unilateral dos conteúdos culturais. Antes, trata-se de conteúdos vivos, atualizados, articulados criticamente com as realidades sociais presentes, selecionados entre os bens culturais 
disponíveis em função de seu valor cultural, formativo e instrumental; mas, simultaneamente, importa conhecer as características socioculturais e psicológicas do aluno, determinadas por condições sociais concretas, de modo a garantir o acesso aos conteúdos a partir da sua prática social; trata-se, enfim, de um saber crítico, não somente valorizando o significado humano e social da cultura, mas também contribuindo para desvelar as contradições da estrutura social que sustenta as relações sociais (p.76).

Para exercer essa prática pedagógica contextualizada e crítica, se requer, igualmente, um educador crítico que "não centra a prática educativa, nem no educando, nem no educador, nem no conteúdo, nem nos métodos, mas a compreende nas relações de seus vários componentes [...]” (FREIRE, 1994, p.110). O que se considera apropriado, no entanto, é que se pode aproveitar e estender os aprendizados da prática pedagógica da escola para outros espaços educativos, fora do ambiente escolar. Nesse sentido, Günther (2006) afirma

[...] que práticas pedagógicas, de modo geral, não estão, necessariamente, restritas ao ambiente escolar, mas podem estar presentes em inúmeras situações em que se estabeleça uma relação de ensino-aprendizagem marcada pela intencionalidade, por um nível de consciência e de planejamento e ainda integre o processo de formação humana (p. 68).

Nessa perspectiva, nos aliamos a posição de Moura e Zuchetti (2006, p. 231) ao considerar que a prática pedagógica, exercida por educadores e que ocorre em ambiente fora da escola, caracteriza-se por uma “educação não escolar”. Faz-se esse registro porque é nesse espaço educativo que o educador social de esporte e lazer exerce a sua prática pedagógica.

Ao se considerar os educadores do PELC como educadores sociais não se assume, aqui, um posicionamento em contraponto aos animadores socioculturais (MARCELLINO, 2003b), ou aos animadores culturais (MELO, 2006), ou aos trabalhadores do lazer SUASSUNA (2009). O que se pretende é reforçar a ação educativa desses educadores e os novos estados ontológicos resultantes da ação dos 
mesmos, que estão vinculados a projetos e programas sociais no campo das políticas públicas de esporte e do lazer.

Chamamos a atenção ainda para outro elemento importante para a compreensão da prática pedagógica: os conhecimentos e saberes construídos no cotidiano, ou seja, os saberes docentes. Para Caldeira (2001, p. 98), esses saberes “são aqueles construídos e apropriados pelos professores ao longo de sua trajetória pessoal e profissional, resultante de sua prática, reflexão e experimentação". É dessa forma que os Educadores Sociais de Esporte e Lazer constroem seus saberes docentes, a partir da convivência com a comunidade, com os alunos e com seus pares.

\section{Gestores e Formadores}

Uma das características distintas da prática pedagógica escolar em relação a não escolar está no sentimento de desejo do aluno [grifo nosso]. Revela a colaboradora Neiva: "a grande possibilidade do PELC, e que eu acho que é a dimensão humana mais interessante e mais rica é que ele lida com o desejo das pessoas. As pessoas frequentam o PELC porque querem e não por obrigação" (entrevista janeiro/2011). O aluno que frequenta a escola o faz por obrigatoriedade legal e social. Já, a participação em programas sociais, em especial de lazer e esporte, não ocorre por nenhuma imposição social, apenas movida pela satisfação pessoal, pelo desejo de estar realizando uma atividade prazerosa.

\section{Educadores Sociais de Esporte e Lazer}

A prática pedagógica do educador social de esporte e lazer se configura como uma ação diferenciada, ao menos se comparada à praticada na escola. Não somente pela 
diversidade de conteúdos, mas também pela abrangência da faixa etária, já que o PELC atende desde crianças até a terceira idade. Além disso, diferencia-se de outros projetos sociais, dada a diversidade de atividades que são oferecidas, como o que ocorria no núcleo de Lucio: “[...] eles tiveram aula de dança, ginástica [...] e o projeto social [outro projeto que ocorria em paralelo com o PELC] é só futebol, vai lá, dava a bola, os guris jogavam bola e deu..." (entrevista abril/2011).

Os saberes docentes se constroem não apenas com a vivência pessoal do educador, mas também na interação com os demais educadores e com a comunidade onde está inserido. Essa aprendizagem será mais construtiva e crítica à medida que a prática for problematizada e discutida com os seus pares (CALDEIRA, 2001). No relato a seguir é possível compreender que os saberes docentes voltados à formação inicial ou à educação escolar ficam muito restritivos para a atuação desse educador no ambiente não escolar. No caso específico do Educador Social de Esporte e Lazer, a atuação passa pela construção dos seus saberes, as relações que ele estabelece com o seu ambiente educativo, com o seu local de trabalho e a comunidade onde ele está inserido, como argumenta Carla:

[...] eu nunca tinha entrado numa vila na minha vida, cheguei lá com o coordenador, ele foi comigo mais o sr. PPP, que era da comunidade. Me apresentaram a comunidade [...]aí já o sr. PPP "Óça! Menina", essa é a realidade da nossa comunidade é com essas pessoas que tu vais ter que trabalhar (entrevista abril/2011).

Com a liderança comunitária, o educador social de esporte e lazer terá acesso aos canais de comunicação com os moradores da comunidade. Essas lideranças ocupam o papel de articulação entre o PELC e os educadores no trabalho dos núcleos. Esse é um limite da formação porque não há um conteúdo específico para preparar um educador social de esporte e lazer a ser um articulador comunitário. Isso também ocorre com a prática pedagógica, porque ela não se consolida somente com a oferta de atividades aos 
moradores; ela se constrói na relação do educador com essa comunidade, na ação, no cotidiano.

A outra possibilidade é a construção desse saber, a partir da própria prática, na relação com o aluno, no cotidiano. Nesse aspecto, Molina Neto (1996) separa a prática pedagógica em quatro categorias: prática de conteúdo - o professor preocupa-se em desenvolver o conteúdo programado e, neste caso, há pouco diálogo com o aluno; prática disciplinadora - o professor é a autoridade e sua preocupação está em manter a disciplina e a ordem em aula; prática reflexivo-emancipadora - o professor tem uma postura reflexiva sobre a sua prática, sobre o seu papel na sociedade; e, prática criativa o professor, diante de condições adversas, cria possibilidades para facilitar a sua prática, e mesmo que essa prática não tenha uma discussão e reflexão de contexto é elogiável pelo seu desprendimento pessoal.

Particularmente, consideramos a prática reflexivo-emancipadora a mais provável para questionar contextos sociais e possibilitar mudanças nas relações sociais. No entanto, a experiência do PELC parece ter propiciado mais a prática criativa, especialmente na relação com o aluno, como descreve Artur:

E aí eles vão aceitando porque, na verdade é o que tu busca é o desejo deles, era o que eu tentava fazer e tentava passar pras pessoas que trabalhavam comigo, esquece que tu tem que ensinar tal coisa, porque tu não vai ensinar nada se eles não quiserem, busca o que eles querem, entendeu. E é isso que eles querem, eles querem 'farra', querem se divertir, eles não querem aquele futebol sério. Só que, se o educador chega com aquela concepção de futebol sério, eles vão fazer aquilo porque já estão acostumados. Agora, se tu propões este espaço livre para eles, entra numa boa (entrevista abri1/2011).

A prática pedagógica dos Educadores Sociais de Esporte e Lazer nos permitiu aprender um olhar diferente sobre as possibilidades de atuação do educador em programas sociais: a preocupação em transformar os eventos em ações estratégicas para promover a integração entre as pessoas e aproximar grupos distintos de uma mesma 
comunidade. Vê-se, aqui, uma mudança de concepção sobre o significado de um evento. Tal busca de integração entre os sujeitos mostra uma intencionalidade nas ações do educador que transcende os aspectos apenas técnicos da sua prática pedagógica.

\section{CONSIDERAÇÕES TRANSITÓRIAS}

A questão que conduziu esta investigação indaga de que modo os Educadores Sociais de Esporte e Lazer relacionam a formação do PELC e a prática pedagógica que realizam nas comunidades que atuam. Os achados do estudo nos permitem argumentar que a formação desenvolvida pelo PELC apresentou contribuições, mas também limitações às necessidades dos educadores sociais de esporte e lazer. Nesse sentido, uma contribuição a ser destacada diz respeito ao papel da formação na ressignificação da concepção de esporte desses educadores, na medida em que o esporte mais voltado ao rendimento parecia ser preponderante no entendimento e na atuação pedagógica iniciais dos educadores sociais de esporte e lazer. Por outro lado, um limite importante à formação se refere ao tempo necessário e ao tempo viável para esse processo de ressignificação. O tempo do gestor e o tempo do educador para respostas e anseios da formação são distintos; enquanto um deseja provocar a reflexão, o outro espera sugestões para auxiliá-lo na prática pedagógica.

Mesmo considerando-se importante a definição de conceitos e os conteúdos teóricos para o trabalho na comunidade, o que parece ser requisitado com mais interesse nas formações são as atividades práticas, especialmente as trocas, as experiências vividas e as possibilidades de soluções para os problemas do cotidiano dos educadores sociais de esporte e lazer. Mais que os conteúdos, as metodologias e as atividades práticas para a experimentação desses conteúdos são interpretadas - em termos de 
expectativa e desejo em relação às propostas de formação - como as de maior relevância para os Educadores Sociais de Esporte e Lazer. Nessa perspectiva, desde a ótica desses educadores, a formação atenderia a duas demandas: novas ideias e sugestões de atuação com os alunos, e, através delas, maior integração entre os colegas.

Outro limite quanto à formação dos Educadores Sociais de Esporte e Lazer identificado no trabalho de campo, diz respeito à ausência de conteúdo específico nas formações para preparar esses educadores para serem, também, um articulador comunitário, premissa do PELC. Por outro lado, a prática pedagógica materializada por esses educadores se constituiu em elemento indutor do processo formativo na medida em que possibilitou situações de aprendizagens e de consolidação das relações comunitárias. Exemplo disso foi a preocupação em transformar os eventos em ações estratégicas para promover a integração entre as pessoas e aproximar grupos distintos de uma mesma comunidade. Vê-se, aqui, uma mudança de concepção sobre o significado de um evento e, portanto, da própria prática pedagógica. Esta, não se faz somente com a oferta de atividades aos moradores; se constrói na relação do educador com a comunidade, no cotidiano e na ressignificação dos espaços e da forma de atuação do educador.

Reconhecemos o significado social do educador social de esporte e lazer como sujeito comprometido com a educação, no seu sentido amplo, e com a abrangência de sua atuação. Ao mesmo tempo, ousamos propor a necessidade de pensar uma formação pedagógica voltada às singularidades do trabalho realizado por esses educadores que atuam em programas sociais. Uma formação que privilegie as articulações entre os educadores e a comunidade, que considere as ressignificações dos espaços educativos - 
diferentes do ambiente escolar - e que compreenda que o cerne do processo educativo se consubstancia nas relações entre os sujeitos em qualquer ambiente físico.

\section{REFERÊNCIAS}

BOGDAN, R. C.; BIKLEN, S. K. Investigação Qualitativa em Educação: uma introdução à teoria e aos métodos. Porto: Porto Editora, 1994.

BRACHT, V. Esporte-Estado-Sociedade. Revista Brasileira de Ciências do Esporte. Campinas, v. 10, n. 2, p. 69-73, jan.1989.

BRASIL. Política Nacional do Esporte. Resolução $n^{0}$ 05/Conselho Nacional do Esporte. Brasília: Ministério do Esporte, 2005.

- Ministério do Esporte. Programa de Formação dos Agentes Sociais de Esporte e Lazer do Programa Esporte e Lazer da Cidade. Brasília, 2008. Disponível em:

http://www.esporte.gov.br/arquivos/sndel/esporteLazer/sistemaFormacaoAgentesSociai s.pdf. Acesso em: 03 jun. 2011.

2010a.
Ministério do Esporte. Orientações para implantação do PELC. Brasília,
em: http://www.esporte.gov.br/arquivos/sndel/esporteLazer/orientacoes.pdf. Acesso em: 03 jun. 2011.

. Política Intersetorial: PELC e PRONASCI. Brasília: Ministério do Esporte/SNDEL, 2010b. v.2

CAMARGO, L. O. de L. Hospitalidade, Lazer, Trabalho e Formação. In: PINTO, Leila Mirtes S. Magalhães (Org.). Lazer, turismo e hospitalidade: desafios para as cidadessede e subsedes de megaeventos esportivos. 2. ed. Brasília: Ideal, 2011. p. 85-93.

CALDEIRA, A. M. S. A formação de professores de educação física: quais saberes e quais habilidades? Revista Brasileira de Ciências do Esporte, Florianópolis, v. 22, n.3, p. 87-103, maio, 2001.

CASTELLANI FILHO, L. (Org.). Gestão pública e política de lazer: a formação de agentes sociais. Campinas: Autores Associados, 2007.

EWERTON, A. N. Análise da Formação Profissional do Programa Esporte e Lazer da Cidade (PELC): o olhar dos Agentes Sociais. Belo Horizonte: UFMG, 2010. Dissertação (Mestrado em Lazer). Escola de Educação Física, Fisioterapia e Terapia Ocupacional, Universidade Federal de Minas Gerais, 2010.

FREIRE, P. Pedagogia da Esperança: um reencontro com a Pedagogia do Oprimido. 3. ed. Rio de Janeiro: Paz e Terra, 1994. 
FREIRE, P. Pedagogia da Autonomia: saberes necessários à prática educativa. 36. ed. Rio de Janeiro: Paz e Terra, 2007.

GOMES, C. L.; MELO, V. A. de. Lazer no Brasil: trajetória de estudos, possibilidades de pesquisa. Movimento, Porto Alegre, v. 9, n. 1, p. 23-44, jan./abr. 2003.

GÜNTHER, M. C. C. A prática pedagógica dos professores de educação física e o currículo organizado por ciclos: um estudo na rede municipal de ensino de Porto Alegre. 2006. Tese (Doutorado em Ciências do Movimento Humano), Escola de Educação Física, Universidade Federal do Rio Grande do Sul, Porto Alegre, 2006.

HARGREAVES, A. Profesorado, Cultura y Postmodernidad: cambian los tiempos, cambia el profesorado. Madrid: Morata, 1996.

HERNÁNDEZ, F. A formação do professorado e a investigação sobre a aprendizagem dos docentes. In: MOLINA NETO, V.; TRIVIÑOS, A. N. S. (Org.). A Pesquisa Qualitativa na Educação Física. 2. ed. Porto Alegre: UFRGS/Sulina, 2004. p. 45-59.

ISAYAMA, H. F. O Profissional da Educação Física como Intelectual: Atuação no âmbito do Lazer. In: MARCELLINO, N. C. (Org.). Formação e Desenvolvimento de Pessoal em Lazer e Esporte. Campinas: Papirus, 2003. p. 59-80.

ISAYAMA, H. F. (Org.); SILVA, S. R. (Org.). Estudos do Lazer: Um Panorama. Rio de Janeiro: Apicuri, 2011. v. 1.

LIBÂNEO, J. C. A democratização da escola pública: a pedagogia crítico-social dos conteúdos. 13. ed. São Paulo: Loyola, 1995.

MARCELlinO, N. C. (Org.). Formação e desenvolvimento de pessoal em lazer e esporte. Campinas: Papirus, 2003a.

. A Formação e o Desenvolvimento de Pessoal em Políticas Públicas de Lazer e Esporte. In: . (Org.). Formação e Desenvolvimento de Pessoal em Lazer e Esporte. Campinas: Papirus, 2003b. p. 09-19.

. et al (Org.). Políticas Públicas de Lazer: formação e desenvolvimento de pessoal. Curitiba: OPUS, 2007.

. (Org.). Políticas Públicas de Lazer. Campinas: Alínea, 2008a.

. Políticas de Lazer: mercadores ou educadores? Os cínicos bobos da corte. In: . (Org.). Políticas Públicas de Lazer. Campinas: Editora Alínea, 2008b, p. 21-

42.

Pedagogia da Animação. 9. ed. Campinas: Papirus, 2009.

MASCARENHAS, F. Entre o Ócio e o Negócio: teses acerca da Anatomia do Lazer. Tese (Doutorado em Educação Física) - Faculdade de Educação, Universidade Estadual de Campinas, 2005a. 
MASCARENHAS, F. Lazer e Utopia: limites e possibilidades de ação política. Movimento, Porto Alegre, v.11, n. 3, p.155-182; set.-dez. $2005 b$.

MELO, V. A. de; ALVES JUNIOR, E. de D. Introdução ao Lazer. Barueri: Manole, 2003.

MELO, V. A. de. A Animação Cultural: conceitos e propostas. Campinas: Papirus, 2006.

MOLINA NETO, V. La cultura docente del Profesorado de Educación Física de las escuelas de Porto Alegre. Tese (Doutorado) - Departamento de Didática e Organização Educativa, Universidad de Barcelona, 1996.

. Etnografia: uma opção metodológica para alguns problemas de investigação no âmbito da Educação Física. In: MOLINA NETO, V.; TRIVIÑOS, A. N. S. (Org.). A Pesquisa Qualitativa na Educação Física. 2. ed. Porto Alegre: UFRGS/Sulina, 2004, p. 107-139.

. et al. Os desafios de formação continuada em educação física: nexos com o esporte, a cultura e a sociedade. In: REZER, R. (Org.). O Fenômeno Esportivo: ensaios crítico-reflexivos. Chapecó: Argos, 2006, p. 45-68.

MOURA, E.; ZUCHETTI, D. T. Explorando cenários: educação não escolar e pedagógica social. Educação Unisinos, São Leopoldo, v. 10, n.3, p. 228-236, 2006.

MUller, Pierre; SUREL, Yves. A Análise das Políticas Públicas. Pelotas: EDUCAT, 2002.

PADILHA, V. (Org.). Dialética do lazer. São Paulo: Cortez, 2006.

PELLEGRIN, A. de. Lazer, corpo e sociedade: articulações críticas e resistências políticas. In: PADILHA, V. (Org.). Dialética do lazer. São Paulo: Cortez, 2006, p.104125.

PEREIRA-PEREIRA, Potyara Amazoneida. Discussões conceituais sobre política social como política pública $\mathrm{e}$ direito de cidadania. In: BOSCHETTI, Ivanete; et al. (Org.). Política Social no Capitalismo: Tendências Contemporâneas. 2. ed. São Paulo: Cortez, 2009. p. 87 - 108.

PINTO, L. M. S. de M. Políticas participativas de lazer. Brasília: SESI/DN, 2006.

SCHAFF, I. A. B. Formação Permanente e suas relações com a Prática Pedagógica dos Professores de Educação Física na Secretaria Municipal de Esportes, Recreação e Lazer de Porto Alegre. 2010. Dissertação (Mestrado em Ciências do Movimento Humano), Escola de Educação Física, Universidade Federal do Rio Grande do Sul, Porto Alegre, 2010. 
SOUZA, Celina. Políticas públicas: uma revisão da literatura. Sociologias. Porto Alegre, Porto Alegre, ano 8, $\mathrm{n}^{\mathrm{o}} 16$, jul/dez 2006, p. 20-45. Disponível em http://dx.doi.org/10.1590/S1517-45222006000200003 Acesso em: 17 fev. 2014.

STIGGER, Marco Paulo. Esporte, lazer e estilos de vida: um estudo etnográfico. Campinas: Autores Associados, 2002.

SUASSUNA, Dulce Maria Filgueira de Almeida. O programa esporte e lazer da cidade: a política de formação para o trabalho e o papel dos agentes sociais. CONGRESSO BRASILEIRO DE CIÊNCIAS DO ESPORTE. Salvador, 2009. Anais... Disponível em: http://www.rbceonline.org.br/congressos/index.php/CONBRACE/XVI/paper/view/1484 /781 Acesso em: 10 set. 2013.

TRIVIÑOS, A. N.S. Introdução à Pesquisa em Ciências Sociais: a pesquisa qualitativa em educação. 18. reimpressão. São Paulo: Atlas, 2009.

WITTIZORECKI, E. S. Mudanças Sociais e Trabalho Docente do Professorado de Educação Física na Escola de Ensino Fundamental: um estudo na Rede Municipal de Ensino de Porto Alegre. Tese (Doutorado em Ciências do Movimento Humano). Escola de Educação Física, Universidade Federal do Rio Grande do Sul, 2009.

\section{Endereço dos Autores:}

Gilmar Tondin

Av. Senador Salgado Filho, 6614

Condomínio Cantegril - 3

Bairro São Lucas - Viamão - RS

Endereço Eletrônico: tondin.gilmar@gmail.com 